\title{
A Case of Brain Herniation and Cerebrospinal Fluid Leakage during Endoscopic Marsupialization of Ethmoid Sinus Mucocele
}

\author{
Song Jae Lee ${ }^{(1 D}$, Sang Gyu Park, Hae Won Choi, and Kyung Rae Kim \\ Department of Otolaryngology-Head and Neck Surgery, College of Medicine, Hanyang University, Seoul, Korea
}

\author{
사골동 점액낭종 조대술 중 발생한 뇌 이탈 및 뇌척수액 비루 1 예 \\ 이송재 · 박상규 · 최해원 · 김경래 \\ 한양대학교 의과대학 이비인후-두경부외과학교실
}

\author{
Received July 22, 2019 \\ Revised January 1,2020 \\ Accepted January 8, 2020 \\ Address for correspondence \\ Kyung Rae Kim, PhD \\ Department of Otolaryngology- \\ Head and Neck Surgery, \\ College of Medicine, \\ Hanyang University, \\ 222 Wangsimni-ro, Seongdong-gu, \\ Seoul 04763, Korea \\ Tel $+82-2-2290-8588$ \\ Fax $+82-2-2293-3335$ \\ E-mail krkim@hanyang.ac.kr
}

Paranasal sinus mucocele is a slowly growing benign cystic lesion. It usually involves the frontal and ethmoid sinuses and can extend to adjacent structures, especially to the orbit, skull base and brain parenchyma. Prompt surgical intervention is needed when symptoms occur. Complete resection of mucocele is approached via endoscopic sinus surgery, while marsupialization is also widely considered. Recently, we encountered a case of spontaneous brain herniation and cerebrospinal fluid leakage during endoscopic marsupialization of ethmoid sinus mucocele. Herein, we report the case with a review of the literature.

Korean J Otorhinolaryngol-Head Neck Surg 2020;63(9):427-31

Key Words Cerebrospinal fluid leakage $\cdot$ Ethmoid sinus $\cdot$ Mucocele.

\section{서 론}

부비동 점액낭종은 호흡상피로 쌓인 양성의 낭종성 병변 으로, 부비동 개구부의 폐쇄로 부비동 내에 점액이 정체 및 축적되어 발생한다. ${ }^{1,2)}$ 부비동 점액낭종은 대부분이 전두동 (60 65\%)에서 발생하며, 사골동(20 25\%)에서도 높은 비율 로 발생한다. 그 외 상악동(10\%)과 접형동(1 2\%)의 순서로 나타난다. ${ }^{2,3)}$ 주 증상은 낭종의 크기가 커지면서 발생하며, 해 부학적으로 부비동이 안구에 인접해 있기 때문에 안구돌출, 안구운동장애, 시력장애, 복시 등의 증상이 주로 발생하며 두통, 후각장애, 코 막힘 증상도 발생한다. ${ }^{4-6)}$

점액낭종의 치료는 보존적 치료와 수술적 치료로 크게 나

This is an Open Access article distributed under the terms of the Creative Commons Attribution Non-Commercial License (https://creativecommons.org/licenses/by-nc/4.0) which permits unrestricted non-commercial use, distribution, and reproduction in any medium, provided the original work is properly cited.
눌 수 있다. ${ }^{3)}$ 점액낭종은 서서히 크기가 증가하기 때문에, 증 상이 없을 경우 경과 관찰을 한다.) 증상이 있는 점액낭종의 경우 수술적 치료를 하게 되며, 비 외 접근법과 비 내 접근법 이 있다. 비 외 접근법은 경두개 접근법과 비중격 경유 접근 을 통해 점액낭종 절제를 할 수 있고, 비 내 접근법은 내시경 을 이용한 낭종의 완전 절제와 조대술이 있다.8) 최근 부비동 내시경 수술이 발달하면서 비 내 접근법을 통한 조대술을 가 장 선호한다. 많은 연구에서 내시경을 이용한 조대술을 추천 하고 있고, 합병증에 대한 보고는 상대적으로 적다.5,9,10

저자들은 10 년 전 부비동 내시경 수술 받은 후 발생한 사 골동 점액낭종에 대해서, 국소마취 하 조대술 시행 중 자발적 으로 발생한 뇌 이탈 및 뇌척수액 유출 증례를 이비인후과와 신경외과적 수술과 약물 치료한 경험을 문헌 고찰과 함께 보 고하는 바이다. 


\section{증 례}

55세 남자 환자가 4일 전부터 시작된 고열 및 두통을 주소 로 내원하였다. 기저질환으로 고혈압과 갑상선 기능 항진증이 있고, 10년 전 부비동 내시경 수술을 받은 과거력이 있었다. 주증상 외에 지속적인 코막힘, 후각저하, 안구통증, 시력저 하, 눈물 과다를 호소하였으며, 타원 입원하여 항생제 치료 하였으나 증상은 개선되지 않았다. 내원 당시 활력 징후는 체온 $36.2^{\circ} \mathrm{C}$, 혈압 $130 / 57 \mathrm{~mm} \mathrm{Hg}$ 였고, 내원 3시간 후 혈압 은 $84 / 50 \mathrm{~mm} \mathrm{Hg}$ 로 떨어졌다. 패혈증을 의심하여 흥부 및 복부 컴퓨터단층촬영을 시행하였고, 이상 소견은 없었다. 이 비인후과 협진으로 시행한 비 내시경 검사에서 우측 중비도 에 종물이 관찰되었다(Fig. 1A). 응급실에서 시행한 뇌 컴퓨 터단층촬영 검사 상 양측 전사골동에 $5 \mathrm{~cm}$ 크기의 조영 되 지 않는 종물이 확인되었으며, 전두개저 골벽 일부가 파괴되 었으며, 병변은 우측 안구강을 침범하고, 내직근을 안구 쪽 으로 밀고 있었다(Fig. 2A and C). 신체 진찰 상 우측 안구 돌출 및 구심성 동공 결손 관찰되었고, 안과 검사상 우측 시 력은 $50 \mathrm{~cm}$ 거리에서 손가락 갯수 식별 가능한 수준이었으 며, 상대 구심성 동공결손 및 빛 간섭 단층 촬영 상 시신경 유 두 창백의 시신경 압박 소견이 있었다. 다른 신경학적 이상 소 견은 없어 사골동 점액낭종에 의한 안와 내 합병증 및 전신 감염으로 진단하였다. 국소 마취 하 조대술을 계획하였으며, 수술 전 부비동 컴퓨터단층촬영에서 두개저 골벽이 얇아진 소견을 재확인하였다(Fig. 2B and D).

우측 중비갑개의 안쪽과 바깥쪽 접근으로 점액낭종의 위 치를 파악한 후(Fig. $3 \mathrm{~A}$ and B) 우측 중비갑개를 일부 절제 하고(Fig. 3 C), 큐렛 및 미세흡입절삭기를 사용하여 종물에
조대술을 시행하였다. 누런색의 악취 나는 화농성 고름이 흘 러나왔고(Fig. 3D), 종물 내 고름흡인 및 세균배양 검사를 했 다. 낭종 내 고름을 충분히 흡인한 후 뇌 이탈 및 뇌척수액 유출 소견이 관찰되었다(Fig. $3 \mathrm{E}$ and F), 즉시 신경외과에서 콜라겐 매트릭스[Duraform ${ }^{\circledR}$ (Codman, Raynham, Massachusetts, USA), Duraseal ${ }^{\circledR}$ (Covidien, Dublin, Ireland)] 제제 를 사용하여 경질막을 봉합했고, 이비인후과에서 Merocel $^{\circledR}$ (Medtronic Xomed, Jacksonville, Florida, USA)로 패킹 시 행 후 수술을 종료하였다. 수술 후 환자 의식 수준은 명료하 고, 두통도 다소 호전되었다. 뇌척수액 유출에 대한 관리로 두부 거상 자세 유지 및 절대 침상 안정을 시행하였고, 완화 제로 산화마그네슘을 처방하였다. 혈압은 수술 후 안정화 되 어 $110 / 70 \mathrm{~mm} \mathrm{Hg}$ 이상 유지되었다. 비강 내 뇌실질 노출로 인한 뇌수막염과 뇌염을 예방하기 위해 vancomycin과 metronidazole 정맥 주사를 사용하였다.

수술 후 1 일차에 침상에서 비강 패킹을 제거하였고, 비 내 시경 상 뇌척수액 유출이 관찰되었다. 수술 후 2일차에 의식 수준은 명료하였고, 비 내시경 상 뇌척수액 유출이 지속적으 로 관찰되어 뇌척수액 검사를 진행하였다. 뇌척수액은 혼탁 하였고, 백혈구 $10250 \mathrm{~mm}^{3}$ 으로 두드러진 감염 소견이 관찰 되었다. 이후 균 배양검사에서 Streptococcus pneumoniae가 동정되었다. 수술 후 27일 차에 두통이 지속되었고, 비 내시경 상에서 뇌척수액 유출 소견 여전히 관찰되어 신경외과에서 골 형성 개두술 및 경막 봉합술을 시행하였다. 수술 후 뇌척 수액 유출은 더 이상 관찰되지 않았고 중추신경계 합병증 없 이 회복 후 퇴원하였다. 퇴원 후 새로운 증상 발생 없이 주기 적인 외래 추적 관찰을 하였고, 수술 후 18 개월 뒤 촬영한 뇌 자기공명 영상에서 조대술 시행 부위 및 주변 뇌실질의 특이
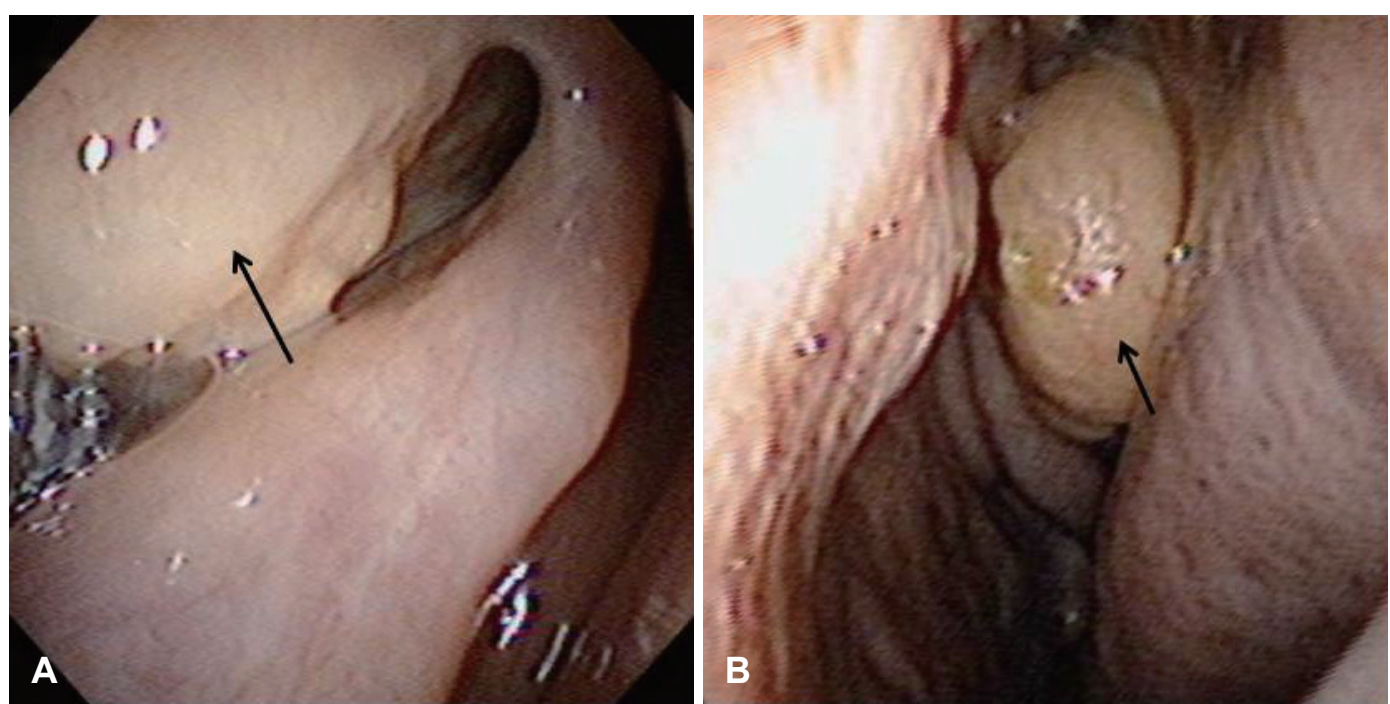

Fig. 1. Preoperative endoscopic findings. Right ostiomeatal unit was blocked by mucocele (arrow) (A). Nasal polyp (arrow) was noted in front of left middle turbinate (B). 

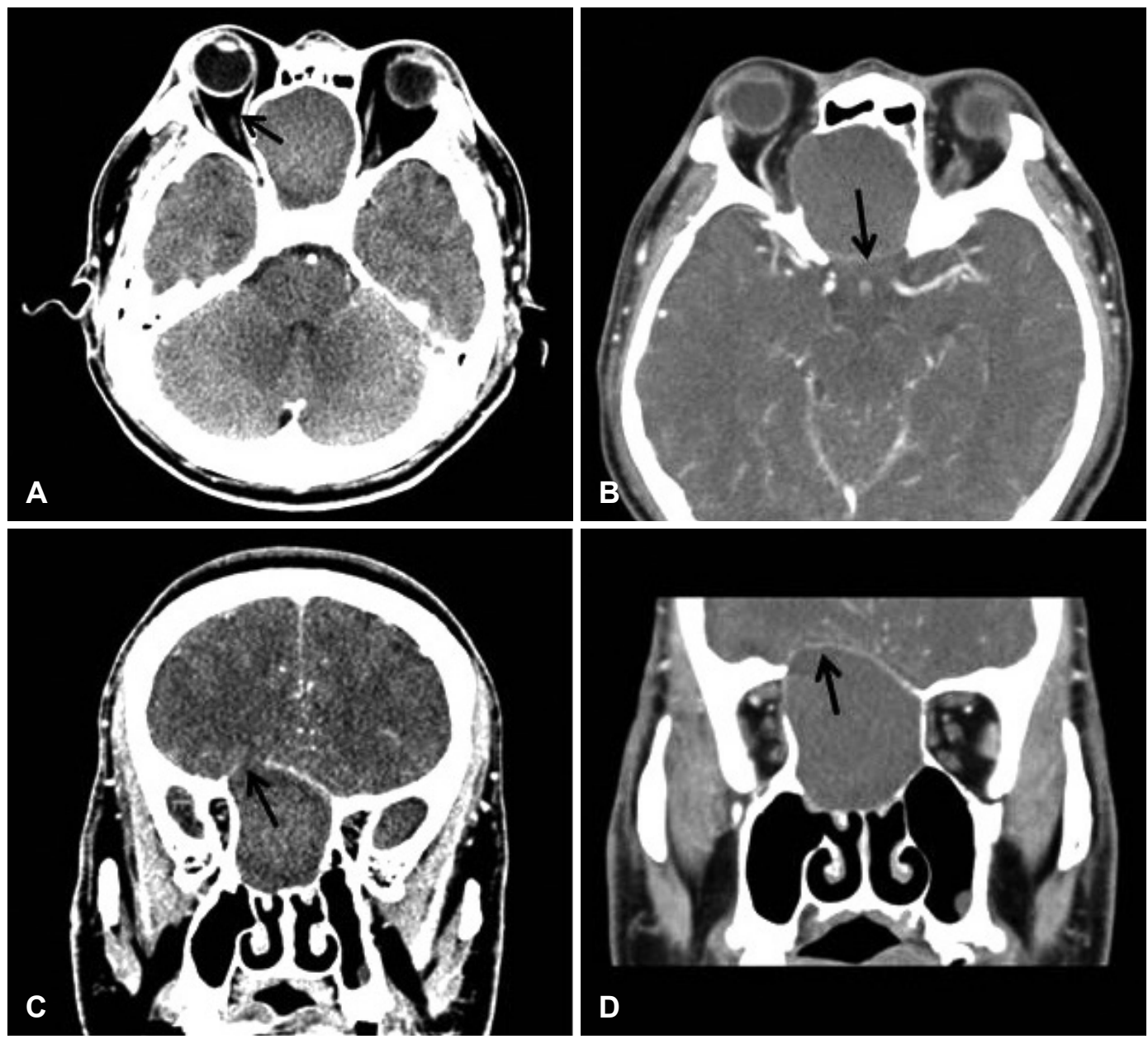

Fig. 2. Brain CT and paranasal sinus CT with contrast enhancement. About $5 \mathrm{~cm}$ sized expansile nonenhancing lesion was noted in both anterior ethmoid sinuses. Bony defect in right medial orbit (arrow) followed by replacement of medial rectus muscle was made by pressure erosion due to mucocele on brain $\mathrm{CT}(\mathrm{A})$. Mucocele was extended to upward, resulting bony defect and thinning of anterior skull base (arrow) on brain CT (C) and PNS CT (B, D).

소견은 관찰되지 않았다(Fig. 4).

\section{고 찰}

점액낭종은 전두동, 사골동, 상악동, 접형동의 모든 부비동 에서 발생 가능하며, 발생 원인이 밝혀지지 않은 원발성 점액 낭종과 수술, 외상, 감염, 방사선, 알레르기, 비용 등에 의해 발생하는 이차성 점액낭종으로 구분 한다.) 모든 연령에서 발 생 가능하며(30 60대가 48\%), 성별의 차이는 없다. ${ }^{5)}$

점액낭종은 느리게 자라면서 서서히 주변 골조직을 압박, 부식하며 골 재형성을 일으킨다. 점액낭종이 부비동 개구부 를 막으면, 감염이 되면서 림프구와 단핵구가 cytokine을 분 비하게 된다. Cytokine은 섬유아세포를 자극해서 PGE2와 collagenase가 분비 되어 골조직이 부식되고, 점액낭종의 크 기는 더 증가하게 된다. ${ }^{4111}$ 점액낭종이 커지면서 다른 부비동, 사대뼈, 두개저 그리고 뇌까지 침범 가능하며, 이중에서 안구
에 가장 많이 침범하게 된다. ${ }^{6}$ 안구돌출, 안구운동장애, 시력 장애, 복시 등의 안구 증상이 대표적으로 발생하며 두통, 후 각장애, 코막힘, 콧물 그리고 드물게 범 뇌하수체 저하증이 나타난다. ${ }^{45}$

증상이 있는 부비동 점액낭종의 치료는 수술적으로 낭종 을 제거하고 개구부를 유지시키는 것이 원칙이다. 비 내 접근 법을 통한 수술적 치료는 크게 두 가지 방식이 있다. 광범위 한 절제로 내벽을 포함하여 점액낭종을 완전히 제거하는 방 법이 있고, 점액낭종의 내벽을 일부 유지하면서 개구부의 병 변을 제거하여 통로를 유지시키는 조대술이 있다. ${ }^{4)}$ 최근 비 내시경의 발달로 내시경을 이용한 조대술이 많이 이용되고 있고, 성공적인 수술 결과들이 보고 되고 있다. ${ }^{59,10)}$ 반면에 합 병증에 관한 보고는 상대적으로 적다.

본 증례의 환자는 10 년 전 부비동 내시경 수술을 받았고, 수술에 의해 이차성 점액낭종이 발생한 것으로 생각된다. 우 리나라에서는 Caldwell-Luc 수술 후 발생하는 상악동 점액 

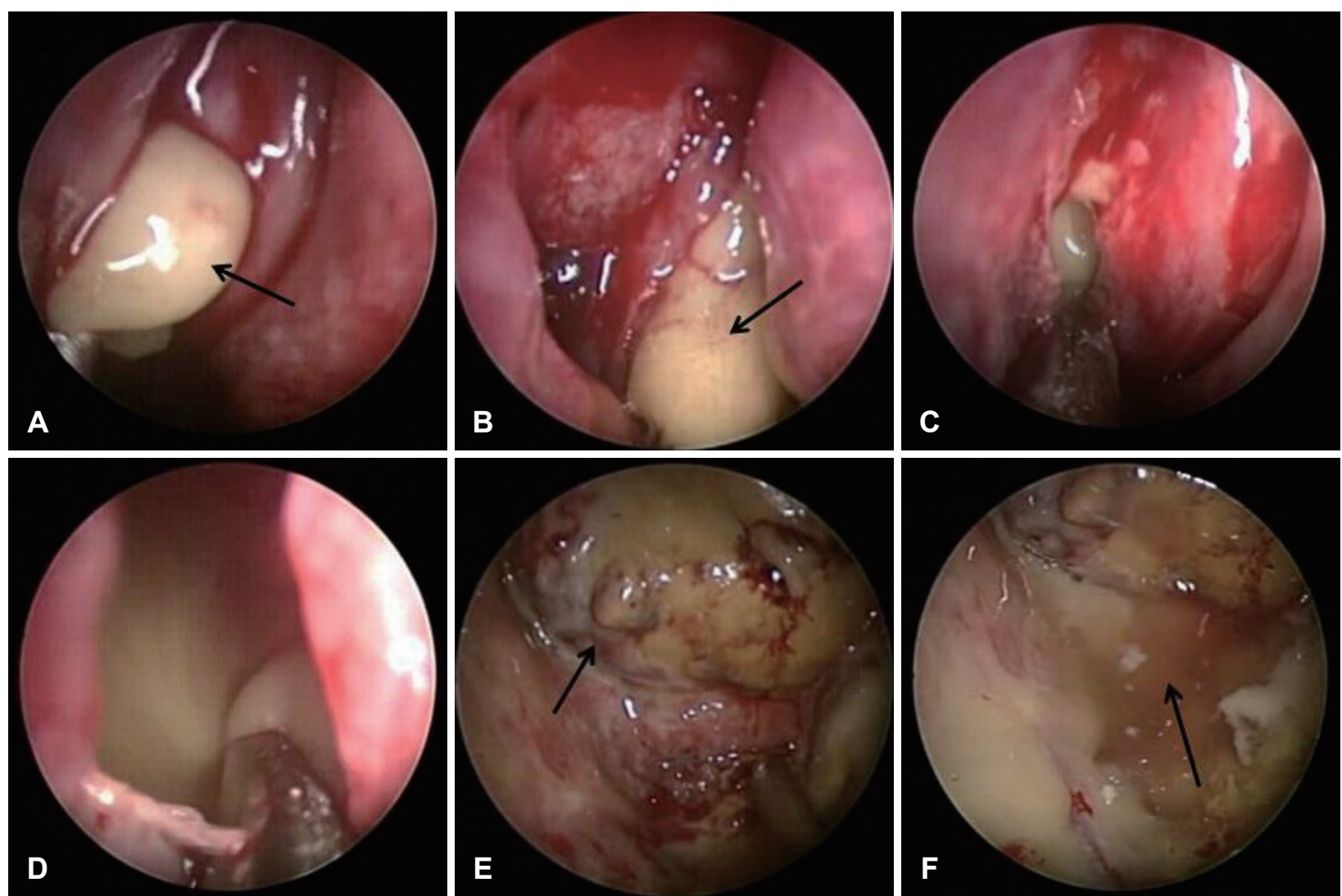

Fig. 3. Operative findings. Yellowish discharge (arrow) was expelled out from lateral side of middle turbinate (A). Yellowish discharge (arrow) was expelled out from medial side of middle turbinate (B). Partial middle turbinectomy was done (C). Large amount of discharge was noted inside mucocele (D). After suctioning discharge, herniated brain covered by mucocele lining (arrow) has been exposed (E). Pulsatile CSF leakage (arrow) was noted (F).
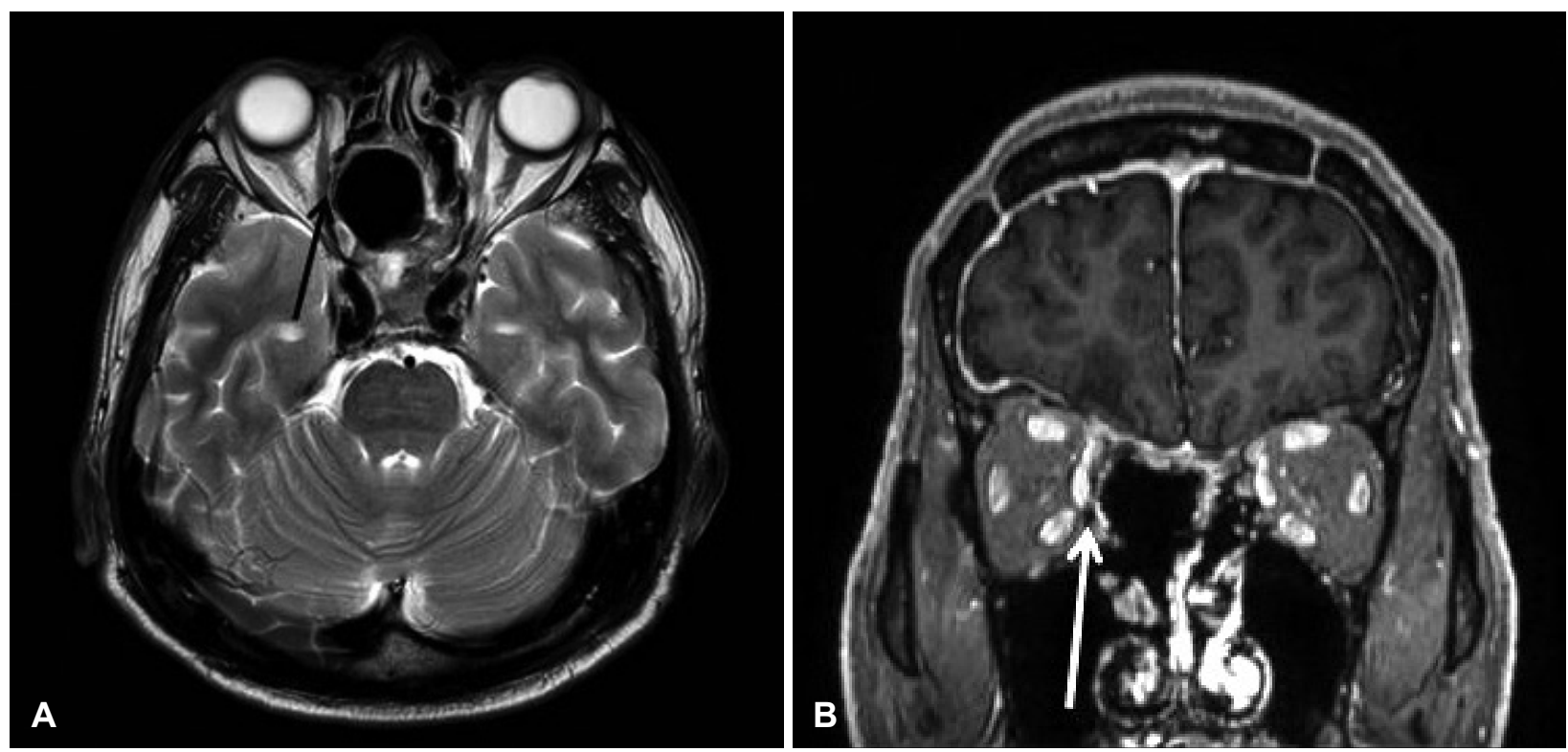

Fig. 4. Postoperative brain MRI with contrast enhancement (18 months after operation). Displacement of right medial rectus muscle on (A) T2 enhanced, axial image (black arrow) and (B) T1 enhanced, coronal image (white arrow) was noted. Otherwise, there was no remarkable abnormality in other brain parenchyma. 
낭종이 부비동 점액낭종의 반 이상을 차지 한다. ${ }^{12)}$ 본 증례와 같은 사골동 점액낭종도 비 외 혹은 비 내 사골동 절제술 시 행 수년 후 발생 할 수 있다. 이전 수술의 흥터 조직이 부비동 개구부를 막거나 부비동 점막을 가두어서 점액낭종을 형성 하게 된다. ${ }^{13)}$

본 증례는 점액낭종이 두개저, 우측 안구강을 침범하면서 두통 및 상대 구심성 동공 결손이 발생하였다. 안와 내 합병 증 및 전신 감염의 위험이 있어 국소 마취 하 응급 수술을 우 선 시행하고 내과적 치료를 하기로 결정하였다. 수술 전 뇌 전산화 단층 촬영에서 두개저 골벽의 일부 파괴는 관찰되었 으나 경질막 손상은 명확히 관찰되지 않았다. 수술은 적절히 진행 되었지만 두개저의 골결손 부위를 통해 뇌이탈 및 뇌척 수액 유출이 발생하였다. 수술 전 신경학적 이상 소견 및 뇌 수막염 의심 소견이 관찰되지 않아서 이에 대한 추가 검사를 시행하지 않고 수술을 우선 시행하였다. 수술 후 뇌척수액 검 사에서 뇌수막염 소견이 관찰된 것으로 미루어 보아 수술 전 에도 뇌수막염의 가능성이 있었고, 뇌수막염이 선행된 상태 에서 조대술로 인한 급격한 압력 변화로 뇌이탈이 발생한 것 으로 생각해 볼 수 있다. 패혈증 의증으로 타원에서 항생제 치료 중이었기 때문에 내원 당시 명확한 뇌수막염의 소견이 관찰되지 않았을 가능성을 생각해 볼 수 있다. 이전 증례 보 고에서 외상에 의한 골파괴로 염증 없는 점액 낭종과 경질막 이 맞닿아 있는 상태에서 조대술로 인한 점액의 이동으로 자 발적인 뇌척수액 유출이 발생하였다. ${ }^{14)}$ 이를 토대로 선행된 뇌수막염이 자발적인 뇌척수액 유출 뿐 아니라 뇌이탈을 가 속화 시켰다고 생각해 볼 수 있다.

경질막이 결손되어 뇌 실질이 노출되는 경우 자가 혹은 동 종의 이식물을 사용하거나 흡수성의 합성 제제를 사용하여 노출 부위를 메우는 수술을 한다. ${ }^{15)}$ 본 증례에서는 예상치 못 하게 뇌 실질 유출을 발견하여 자가 이식물은 사용하지 못하 고 합성 제제를 사용하여 유출 부위를 메웠다. 신경외과와 함 께 두 차례의 수술적 치료를 진행하였고 두개 내 합병증 없이 환자는 증상이 호전되었다.

본 증례처럼 점액낭종의 크기가 크고 두개저의 손상이 동 반된 경우 뇌염, 뇌수막염, 경막염, 수두증, 경막외 농양, 뇌농 양과 더불어 자발적인 뇌척수액 유출, 뇌이탈 등의 합병증이 발생할 가능성이 있다. 특히 뇌이탈은 의식의 변화나 뇌기능 및 생명 유지에도 큰 영향을 미칠 수 있는 심각한 합병증이 다. 수술에 앞서 가능하다면 뇌 자기 공명 영상 촬영을 시행 하여 주변 구조물들과의 경계 및 낭종의 성상에 대해서 우선 확인해 보는 과정이 필요하다. 또한 수술 중 결손이 관찰된 경우 결손 범위 확인 및 즉각적인 교정술이 필요하다.

\section{Acknowledgments}

None.

\section{Author Contribution}

Conceptualization: Song Jae Lee, Kyung Rae Kim. Funding acquisition: Kyung Rae Kim. Resources: Kyung Rae Kim. Supervision: Kyung Rae Kim. Visualization: Song Jae Lee, Sang Gyu Park. Writing - original draft: Song Jae Lee, Hae Won Choi. Writingreview\&editing: Song Jae Lee, Kyung Rae Kim.

\section{ORCIDs}

Kyung Rae Kim https://orcid.org/0000-0003-2196-8267

Song Jae Lee https://orcid.org/0000-0003-0439-1427

\section{REFERENCES}

1) Aggarwal SK, Bhavana K, Keshri A, Kumar R, Srivastava A. Frontal sinus mucocele with orbital complications: Management by varied surgical approaches. Asian J Neurosurg 2012;7(3):135-40.

2) Carvalho BVD, Lopes IDCC, Corrêa JdB, Ramos LFM, Motta EGPC, Diniz RLFC. Typical and atypical presentations of paranasal sinus mucocele at computed tomography. Radiol Bras 2013;46(6): $372-5$.

3) Bang SH, Kim DC, Kim JG. Endoscopic sinus surgery for pyocele of frontochemoidal sinuses. Korean J Otolaryngol-Head and Neck Surg 1991;34(3):561-6.

4) Kim SS, Kang SS, Kim KS, Yoon JH, Lee JG, Park IY. Clinical characteristics of primary paranasal sinus mucoceles and their surgical treatment outcome. Korean J Otolaryngol-Head and Neck Surg 1998;41(11):1436-9.

5) Caballero GJ, Giol AAM, Morales PI, Gonzales GN, Hidalgo GA, Cruz PP. Endoscopic treatment of sphenoid sinus mucocele: Case report and surgical considerations. Case Rep Otolaryngol 2017; 2017:1-4.

6) Gendeh BS. Paranasal sinus mucoceles - opthalmic manifestations, radiological imaging, endoscopic endonasal marsupilization and outcome. In: Davey P, editors. Ophthalmology Current Clinical and Research Updates. 3rd ed. London: IntechOpen;2014.

7) Sadhoo A, Tuli IP, Sharma N. Idiopathic mucocele of maxillary sinus: A rare and frequently misdiagnosed entity. J Oral Maxillofac Radiol 2016;4(3)87-9.

8) Tinoco P, Pereira JCO, Filho RCL, Silva FBC. Nasoendoscopic treatment of the sphenoid sinus mucoceles. Int Arch Otorhinolaryngol 2009;13(3):336-9.

9) Chung J, Sim YC, Lee DH, Lee JH. A case of primary septated mucocele of maxillary sinus. Korean J Otorhinolaryngol-Head Neck Surg 2016;59(12):865-8.

10) Wie CE, Hong SL, Mun SJ, Cho KS. Endoscopic marsupialization of frontoethmoid mucocele with underlying craniofacial fibrous dysplasia. J Craniofac Surg 2015;26(1):e73-4.

11) Caylakli F, Yavuz H, Cagici AC, Ozluoglu LN. Endoscopic sinus surgery for maxillary sinus mucoceles. Head Face Med 2006;2(1):29.

12) Song HM, Park HW, Chung YS, Jang YJ, Lee BJ. Primary mucoceles of the maxillary sinus. Korean J Otolaryngol-Head Neck Surg 2006;49(1):47-51.

13) Busaba NY, Salman SD. Ethmoid mucocele as a late complication of endoscopic ethmoidectomy. Otolaryngol Head Neck Surg 2003; 128(4):517-22.

14) Kim SH, Jung J, Mun SJ, Roh HJ. A case of frontoethmoidal mucopyocele combined with cerebrospinal fluid leak and complicated tension pneumocephalus after marsupialization. J Rhinol 2018; 25(1):38-42.

15) Zweig JL, Carrau RL, Celin SE, Schaitkin BM, Pollice PA, Snyderman $\mathrm{CH}$, et al. Endoscopic repair of cerebrospinal fluid leaks to the sinonasal tract: Predictors of success. Otolaryngol Head Neck Surg 2000;123(3): 195-201. 